\title{
Intelligent oxygen delivery in the acute setting: "Don't think twice, it's all right"
}

\author{
João Carlos Winck ${ }^{1,2}$ \\ Affiliations: ${ }^{1}$ Centro de Reabilitação do Norte, Valadares, Portugal. ${ }^{2}$ Faculdade de Medicina da Universidade \\ do Porto, Porto, Portugal.
}

Correspondence: João Carlos Winck, Faculdade de Medicina do Porto - Pulmonology, Alameda Prof Hernani Monteiro, Porto 4200-319, Portugal. E-mail: jcwinckamail..pt

@ERSpublications

Automated targeted oxygen therapy improves oxygen titration in the acute setting http://ow.ly/B2sw30cAalO

Cite this article as: Winck JC. Intelligent oxygen delivery in the acute setting: "Don't think twice, it's all right”. Eur Respir J 2017; 50: 1701013 [https://doi.org/10.1183/13993003.01013-2017].

In 1917 Haldane published "The therapeutic administration of oxygen" and started the era of oxygen therapy [1]. Nowadays, supplemental oxygen is a vital part of pre-hospital and hospital trauma care, the practice of anaesthesia, the management of most forms of respiratory distress and the treatment of many other acute and chronic medical conditions [2].

In fact, oxygen therapy has become a cornerstone of modern medical practice. Oxygen is one of the most frequently used drugs in the emergency setting [3]. However the current practice of prescribing oxygen therapy is poor and improves slowly after guideline implementation [4]. Apart from the well-known risks of hypoxaemia and hyperoxaemia in COPD [5], new evidence suggests hyperoxia may have deleterious effects on other critically ill patients $[6,7]$.

So, conservative oxygen therapy represents the treatment of choice to avoid exposure to both hypoxaemia and excess hyperoxaemia.

Oxygen therapy should be considered like a drug prescription and so careful titration should be pursued [8]. Like intravenous infusion pumps that have become routine for precise dosage of drugs, oxygen should be also be tightly controlled. As demonstrated for intelligent infusion pumps [9] that reduce the likelihood of intravenous anticoagulant overdose or underdose, if implemented in our hospitals targeted oxygen therapy may result in the reduction of its potential side effects.

Accordingly, for insulin therapy, it has been demonstrated that hybrid closed loop automated insulin delivery is associated with few serious or device related adverse events in patients with type 1 diabetes $[10,11]$.

The need of targeted automated oxygen therapy has been established previously for preterm infants with the aim to reduce the risk of complications from hypoxaemia or hyperoxaemia [12].

In a recently published meta-analysis [13], including four trials in infants and one in adults [14-18], compared to manual oxygen titration, automated systems increase the length of time that oxygen saturation was maintained within a pre-defined range, confirming they achieve a better oxygenation.

The use of these newer automated oxygen delivery systems may also potentially save time, freeing nurses to engage in other tasks, which would be expected to result in safer care [19].

Received: May 172017 | Accepted: May 182017

Conflict of interest: None declared.

Copyright OERS 2017 
There are different closed-loop systems for automated oxygen delivery [20-22], each one with its own algorithm (with different reaction times, frequency of adjustment, response to artefacts or poor signal quality) more adapted to acute or chronic setting, infants [16] or adults [23].

L'Her et al. [24], in the largest multicentre randomised controlled trial of automated oxygen titration of patients with acute respiratory failure, found that the closed-loop system achieved a better control of oxygenation, with a shorter duration of oxygen therapy and hospital stay.

In their 3-h study period, with an already validated device [20] they used different targets for oxygenation for pure hypoxemic and hypercapnic patients and showed no difference in adverse events between groups (automatic versus manual titration).

This study leaves some potential unanswered questions: Does the system described by L'HeR et al. [24] have the same performance with different interfaces (the face mask used here versus the nasal cannula in their previous studies [23])? Is the oximeter used sensitive enough to correct artefactual causes of hypoxaemia (like low perfusion and motion)?

How we can advance the system forward?

Some features of the device could be incorporated like being able to transfer the data to a nurses' station and to the patient electronic record to view and register the trends and alerts.

The equipment could also include weaning algorithms or automated intervals if necessary and warning on the underlying patient condition (like an acute myocardial infarction or stroke in which oxygen therapy may be harmful for non-hypoxemic patients $[25,26])$.

Other important issues may be alarms related to eventual false hypoxaemic events due to motion artefacts, making the professional aware of the situation for evaluation. In addition, warning of persistent increases of inspiratory oxygen fraction by the device should be included in order to prompt the professional to a careful assessment. Moreover, in the future, as the clinical evidence emerges, the software could also suggest the targets according with the disease category: for different types of type 1 failure (pneumonia versus pneumothorax versus acute cardiogenic pulmonary oedema).

As happened with the valuable infusion pumps, some safety issues may arise in the future. Like other devices, these oxygen closed-loop systems may suffer from malfunctions (like software defects or electrical failures) that may cause some adverse events. Similar to other medical equipment, electromagnetic interference secondary to mobile phones with these devices should also be checked [27].

Therefore, close auditing of these systems is highly warranted. In the end, these automated systems can reduce the workload of the caregiver [19] but should not reduce the attention of the caregiver to the patient's lung function status. Perhaps in the years ahead (especially for more severe patients than the ones included in the ERJ trial) there will be systems that run, in parallel, a ventilation and an oxygenation closed-loop system [28].

In an era of precision medicine, the current study published in the ERJ [24] confirms the efficacy of this automated closed loop inspiratory oxygen fraction system for adults with acute respiratory failure, and suggests a "one size fits all" approach may no longer be supported. Long-term studies with other clinical outcomes and cost-benefit analyses are warranted. In the meantime, I say, like the Bob Dylan song: "Don't think twice, it's all right"!

\section{Acknowledgement}

This editorial is dedicated to my late father José Guilherme Cruz, who passed away at 99, while I was preparing it.

\section{References}

1 Haldane JS. The Therapeutic Administration of Oxygen. Br Med J 1917; 1: 181-183.

2 O'Driscoll BR, Howard LS, Davison AG, et al. BTS guideline for emergency oxygen use in adult patients. Thorax 2008; 63: Suppl 6, vil-vi68.

3 Hale KE, Gavin C, O'Driscoll BR. Audit of oxygen use in emergency ambulances and in a hospital emergency department. Emerg Med J 2008; 25: 773-776.

4 O'Driscoll BR, Howard LS, Bucknall C, et al. British Thoracic Society emergency oxygen audits. Thorax 2011; 66: 734-735.

5 Cameron L, Pilcher J, Weatherall M, et al. The risk of serious adverse outcomes associated with hypoxaemia and hyperoxaemia in acute exacerbations of COPD. Postgrad Med J 2012; 88: 684-689.

6 Girardis M, Busani S, Damiani E, et al. Effect of conservative vs conventional oxygen therapy on mortality among patients in an intensive care unit: The Oxygen-ICU Randomized Clinical Trial. JAMA 2016; 316: 1583-1589.

7 Asfar P, Schortgen F, Boisrame-Helms J, et al. Hyperoxia and hypertonic saline in patients with septic shock (HYPERS2S): a two-by-two factorial, multicentre, randomised, clinical trial. Lancet Respir Med 2017; 5: 180-190.

8 Bitterman H. Bench-to-bedside review: oxygen as a drug. Crit Care 2009; 13: 205. 
9 Fanikos J, Fiumara K, Baroletti S, et al. Impact of smart infusion technology on administration of anticoagulants (unfractionated Heparin, Argatroban, Lepirudin, and Bivalirudin). Am J Cardiol 2007; 99: 1002-1005.

10 Anderson D, Phelan $\mathrm{H}$, Jones $\mathrm{K}$, et al. Evaluation of a novel continuous glucose monitoring guided system for adjustment of insulin dosing - PumpTune: a randomized controlled trial. Pediatr Diabetes 2016; 17: 478-482.

11 Bergenstal RM, Garg S, Weinzimer SA, et al. Safety of a hybrid closed-loop insulin delivery system in patients with type 1 diabetes. JAMA 2016; 316: 1407-1408.

12 Claure N, Bancalari E. Automated closed loop control of inspired oxygen concentration. Respir Care 2013; 58: $151-161$.

13 Brogi E, Cyr S, Kazan R, et al. Clinical performance and safety of closed-loop systems: a systematic review and meta-analysis of randomized controlled trials. Anesth Analg 2017; 124: 446-455.

14 Claure N, Gerhardt T, Everett R, et al. Closed-loop controlled inspired oxygen concentration for mechanically ventilated very low birth weight infants with frequent episodes of hypoxemia. Pediatrics 2001; 107: 1120-1124.

15 Claure N, Bancalari E, D'Ugard C, et al. Multicenter crossover study of automated control of inspired oxygen in ventilated preterm infants. Pediatrics 2011; 127: e76-e83.

16 Hallenberger A, Poets CF, Horn W, et al. Closed-loop automatic oxygen control (CLAC) in preterm infants: a randomized controlled trial. Pediatrics 2014; 133: e379-e385.

17 Urschitz MS, Horn W, Seyfang A, et al. Automatic control of the inspired oxygen fraction in preterm infants: a randomized crossover trial. Am J Respir Crit Care Med 2004; 170: 1095-1100.

18 Johannigman JA, Branson R, Lecroy D, et al. Autonomous control of inspired oxygen concentration during mechanical ventilation of the critically injured trauma patient. J Trauma 2009; 66: 386-392.

19 Sink DW, Hope SA, Hagadorn JI. Nurse:patient ratio and achievement of oxygen saturation goals in premature infants. Arch Dis Child Fetal Neonatal Ed 2011; 96: F93-F98.

20 Lellouche F, L'Her E. Automated oxygen flow titration to maintain constant oxygenation. Respir Care 2012; 57: $1254-1262$.

21 Cirio S, Nava S. Pilot study of a new device to titrate oxygen flow in hypoxic patients on long-term oxygen therapy. Respir Care 2011; 56: 429-434.

22 Rice KL, Schmidt MF, Buan JS, et al. AccuO2 oximetry-driven oxygen-conserving device versus fixed-dose oxygen devices in stable COPD patients. Respir Care 2011; 56: 1901-1905.

23 Lellouche F, Bouchard PA, Roberge M, et al. Automated oxygen titration and weaning with FreeO2 in patients with acute exacerbation of COPD: a pilot randomized trial. Int J Chron Obstruct Pulmon Dis 2016; 11: 1983-1990.

24 L'Her E, Dias P, Gouillou M, et al. Automatic versus manual oxygen administration in the emergency department. Eur Respir J 2017; 50: 1602552.

25 Stub D, Smith K, Bernard S, et al. Air versus oxygen in ST-segment-elevation myocardial infarction. Circulation 2015; 131: 2143-2150.

26 Kallet RH, Branson RD. Should oxygen therapy be tightly regulated to minimize hyperoxia in critically ill patients? Respir Care 2016; 61: 801-817.

27 Lawrentschuk N, Bolton DM. Mobile phone interference with medical equipment and its clinical relevance: a systematic review. Med J Aust 2004; 181: 145-149.

28 Arnal JM, Garnero A, Novonti D, et al. Feasibility study on full closed-loop control ventilation (IntelliVent-ASV) in ICU patients with acute respiratory failure: a prospective observational comparative study. Crit Care 2013; 17: R196. 